\title{
La familia: sujeto y objeto del cambio social
}

\author{
Isabel Marín Gómez \\ Manuela Avilés Hernández \\ Universidad de Murcia
}

Aunque no están claros los orígenes de la familia ni las etapas que ésta ha ido atravesando en el curso de su desarrollo, todo induce a pensar, afirma el antropólogo Ralph Linton, que "la familia es la más antigua de las instituciones sociales humanas" $y$, además, "una institución que sobrevivirá, en una forma u otra, mientras exista nuestra especie" (1977: 5).

De las palabras de Linton se desprenden dos ideas fundamentales. La primera es que la institución familiar se encuentra estrechamente vinculada a la especie humana, por lo que ha estado, y seguirá estando, presente en la historia de la humanidad. En ella, además, ha ocupado un lugar privilegiado, hasta el punto de que, como plantean los sociólogos Josep Picó y Enric Sanchis (2003), son muchos los autores que han coincidido en señalar que la familia es una institución social básica e, incluso, la célula principal de la sociedad, dado que la gran mayoría de individuos han crecido en un contexto familiar.

La segunda idea que observamos es que la familia no es una realidad estática, que permanezca invariable a lo largo de la historia. Todo lo contrario. Es una institución dinámica que, para poder perdurar en el tiempo, para poder "sobrevivir" en palabras del propio Linton, debe ir adoptando distintas formas y experimentando, por consiguiente, numerosas transformaciones, todas ellas ligadas íntimamente a los cambios sufridos por la sociedad. Como indica la especialista en demografía Ángeles Valero, "aunque la familia constituye una institución universal, las características propias de las distintas sociedades humanas, sus sistemas económicos y su cultura determinan la forma adoptada por esta institución en cada sociedad y momento histórico concreto" (1995: 91).

El historiador David-Sven Reher (1996) apunta que algunas de las figuras más destacadas en el campo de las Ciencias Sociales, como Frédéric Le Play, Benjamin Rowntree o Alexander Chayanov, han entendido, con énfasis diferentes, que la familia, además de estar condicionada por el entorno social, económico, demográfico y cultural que la rodea, tiene capacidad para actuar e influir sobre el mundo circundante, pudiendo contribuir a configurar las características de la sociedad en la que se encuentra. De este modo, aclara Reher, la institución familiar puede actuar como una variable dependiente e independiente, es decir, puede ser, al mismo tiempo, sujeto y objeto de la época histórica y de la sociedad en la que se halla.

Esta dualidad que caracteriza a la familia puede apreciarse al analizar la doble finalidad que históricamente ha tenido asignada. Por una parte, se ha encargado de "defender, proteger y asegurar lo mejor posible la supervivencia y bienestar de sus propios miembros en circunstancias muchas veces difíciles y adversas"; por otra, ha sido "garante de la reproducción social, económica y demográfica de la sociedad" (Reher, 1996: 23 y 24). Según las observaciones de Reher a este respecto, la capacidad de la familia para cumplir cualquiera de ellas ha estado, y seguirá estando, condicionada por el contexto en el que se inserta. De ahí que, para alcanzar la consecución de ambas, deba adaptarse a los cambios acaecidos en la realidad, actuando como una institución dependiente del entorno que la rodea. De igual forma, añade Reher, la familia es un grupo en el que se toman decisiones racionales y se aplican estrategias a corto y largo plazo, con el objetivo de alcanzar la doble finalidad que tiene asignada. Por eso, en ocasiones, con sus actos, puede influir sobre la sociedad, modificándola de diversas maneras o en distintas direcciones, funcionando, de esta forma, como una variable independiente.

De acuerdo con estas premisas, se puede concluir que la familia es una institución social antigua y de gran importancia no solo para los individuos que la componen, sino también para la propia sociedad en la que se encuentra. Igualmente, es una institución que se ve fuertemente influenciada por la realidad que la rodea, pero sobre la que, a su vez, puede actuar, desempeñando así un papel activo en los procesos de cambio social. La relación entre familia 
y cambio social es, por tanto, estrecha, y goza de un marcado carácter bidireccional. En ello coincide, igualmente, la amplia trayectoria historiográfica, sobre todo desde que apareciera su tendencia en Historia Social, con numerosos estudios y temáticas en torno a la Historia de la Familia y sus interrelaciones en los cambios sociales (Hernández Franco e Irigoyen López, 2020).

En este monográfico, titulado Familia y Cambio Social, se profundiza de manera concreta en esa doble naturaleza que caracteriza a la institución familiar: por una parte, como sujeto, en ocasiones protagonista del cambio social, $y$, por otra, como objeto, pasivo o no, del mismo. A lo largo de los catorce artículos que lo componen, se revisan algunas de las transformaciones más radicales que la familia ha experimentado hasta llegar a su configuración actual, sin olvidar la capacidad que, a su vez, ha tenido, y sigue teniendo, para impulsar cambios diversos y profundos en ámbitos de su entorno más inmediato como el sistema jurídico, las escuelas, los servicios de protección y atención social, el marco legislativo y de las políticas públicas, etc. Se revisan cuestiones específicas como los cambios estructurales que han sufrido las familias, la evolución de las relaciones interpersonales dentro del núcleo familiar, los conflictos familiares actuales y su posible abordaje a través de estrategias innovadoras como la mediación, la intervención profesional desde las políticas sociales, la relación entre familia y entorno educativo, etc. La temática se aborda desde un enfoque multidisciplinar, pues los dieciocho expertos y expertas en la materia que participan en este monográfico pertenecen a distintas áreas de conocimiento: Historia, Antropología, Sociología, Trabajo Social, Educación, Ciencias Políticas y Derecho. También, se presenta desde una perspectiva internacional, al contar con investigadores/as de distintos países, en concreto España, Portugal y México.

El monográfico comienza con el artículo "De la historia «en migajas» a los objetos sólidos. Nuevos retos conceptuales, teóricos y metodológicos sobre Familia y ciencias sociales", escrito por el Catedrático de Historia Moderna de la Universidad de Murcia (España), Francisco Chacón Jiménez. En este artículo, que tiene un importante carácter contextual, el autor profundiza, desde un enfoque sociohistórico, en el papel protagonista que las familias, en plural, han tenido sobre el cambio social, y también sobre las resistencias al mismo. Se trata de un análisis teórico y epistemológico respecto al enfoque historiográfico, en el que se determinan factores clave como jerarquía, genealogías intergeneracionales, dominación, desigualdad y dependencia.

El siguiente artículo se centra en un tipo de estructura familiar que ha estado presente a lo largo de toda la historia, pero que ha adquirido más visibilidad recientemente, con la generalización de los divorcios y separaciones conyugales. Se trata de las familias monoparentales. Manuela Avilés Hernández, profesora en la Universidad de Murcia (España), analiza la situación económica que presentan estas familias actualmente en España. Profundiza en cuestiones como la seguridad económica, la situación material o el riesgo de pobreza al que están expuestas. De manera concreta, se detiene en el impacto que la pandemia ocasionada por la COVID-19 ha podido tener sobre las condiciones de vida de los hogares formados por estos grupos familiares. El análisis lo realiza a partir de los datos oficiales que ofrece la Encuesta de Condiciones de Vida de 2020, realizada por el Instituto Nacional de Estadística de España.

Marcela Jabbaz Churba, profesora en la Universitat de València (España), nos presenta a continuación el artículo que lleva por título "Infancia alterada en pleitos por la custodia de menores". En este caso, el análisis se centra en los procesos de divorcio y en cómo éstos afectan a los menores. Sobre todo, se profundiza en las disputas que surgen entre madres y padres por la custodia y el régimen de visitas de sus hijos e hijas. Mediante una interpretación de las narrativas de los progenitores, se estudia la situación previa al divorcio, las vivencias a lo largo del proceso judicial y las relaciones entre la expareja una vez que se han tomado las medidas judiciales definitivas con relación a los menores.

El siguiente artículo se centra en otro tipo de familia que ha ido en aumento con la llegada del nuevo siglo. Se trata de las familias adoptantes. En este caso, el foco de atención no se pone concretamente en éstas, sino en las familias biológicas, analizando el papel que desempeñan en el proceso de adopción del menor. Ana Chacón Martínez, profesora en la Universidad de Murcia (España), analiza cuáles son las características y rasgos sociales de las familias biológicas de niños y niñas que fueron adoptados en la Comunidad Autónoma de la Región de Murcia entre 1987 y 2007 . El objetivo es reflexionar sobre si estas familias fueron excluidas de la adopción por sus características, al estar enmarcadas en contextos problemáticos graves, que acentúan el riesgo para los menores.

El artículo escrito por Diana Lanzarote Fernández, de la Universidad de Murcia (España), se centra en las familias homoparentales, que son aquellas en las que los dos miembros de la pareja son del mismo sexo. En su artículo estudia, de forma concreta, a las familias homoparentales femeninas en las que hay descendencia. A través de una metodología cualitativa, explora la experiencia de la maternidad lesbiana, reconociéndola como una experiencia genuina en lo referente a las formas de parentesco.

Emilia Iglesias Ortuño (Universidad de Murcia, España) y Cristina Ulloa Espinosa (ITESO Universidad Jesuita de Guadalajara, México), se centran, en el siguiente artículo, en la mediación de conflictos familiares y en sus aportaciones al cambio sociocultural de la familia mexicana. Plantean que la familia de este país se encuentra en constante cambio, debido a cuestiones como las transformaciones en la configuración familiar, la redistribución de roles, especialmente de género, los procesos de vinculación intergeneracional, los fenómenos migratorios, los traslados del espacio rural a las ciudades, la diversidad étnica, etc. Todos estos aspectos implican tensiones y conflictos dentro de la propia unidad familiar. Por eso, los Métodos Alternos de Solución de Conflictos, en especial la Mediación, se conciben como una estrategia de gestión positiva, pacífica y constructiva de esos conflictos, garantizando el bienestar familiar y la comunicación intrafamiliar.

En el siguiente artículo, titulado "Familia y Tecnociencia: ¿qué nos depara el futuro inmediato?", Joaquín Guerrero Muñoz, profesor en la Universidad de Murcia (España), y Luís Álvarez Munárriz, Catedrático de Antropología Social de esta misma Universidad, revisan la repercusión que los 
recientes avances de la Ingeniería genética, especialmente de la Edición de Genes (CRISPR), puede tener en la institución familiar. En concreto, analizan las disputas que están generando cuestiones como la clonación o la reciente modificación de embriones.

Sin duda, la COVID-19 ha afectado decisivamente a las relaciones familiares, y, entre los más afectados, las personas mayores, población mayoritaria, que, viéndose sometida al distanciamiento social, ha visto agravada su situación en todos los aspectos, incluida la limitación en la participación social, imprescindible para evitar los sentimientos de soledad que ya lleva implícito el envejecimiento. Elvira Medina Ruiz, profesora de la Universidad de Murcia (España), en el artículo titulado "Personas mayores, participación y cambio social antes y después del COVID-19", profundiza en este fenómeno, cuyo estudio resulta necesario por la extraordinaria dimensión pública que tienen las personas mayores en las esferas públicas y privadas, y especialmente en la familiar.

Por su parte, la profesora de la Universidad Autónoma de Nuevo León (México), Blanca Mirthala Tamez Valdez, en el artículo titulado "Transformaciones familiares y política social en el México contemporáneo", además de profundizar en la situación de los grupos familiares en el México de las últimas décadas, caracterizada por la gran heterogeneidad de los grupos familiares, aborda las estrategias familiares en la vida cotidiana para la obtención de recursos de subsistencia; la organización del cuidado; las habitacionales; las de los procesos de salud-enfermedad y las de aprendizaje y uso del tiempo libre, dando cuenta de las transformaciones y permanencias a las que dichas estrategias van dando lugar al tener que enfrentarse a las presiones de la política social, y a las dificultades que ésta presenta para dar respuestas a las crecientes necesidades materiales y subjetivas de los grupos familiares.

El artículo de Isabel Marín Gómez, profesora de la Universidad de Murcia (España), afronta el problema de interrelacionar tres fenómenos históricos que son inherentes: Género, Familia y Cambio Social, en los que se ponen de manifiesto las desigualdades milenarias que le afectan y, por tanto, las enormes dificultades que presenta su estudio por su complejidad omnicomprensiva. Remite para ello al análisis ensayístico, planteando el problema desde el proceso historiográfico de la Historia Social, la Historia de Género y la Historia de la Familia, que se han desarrollado de manera paralela, para poder entender cómo surge la cuestión de género, la pluridimensionalidad que le caracteriza históricamente en todos los ámbitos del conocimiento científico, cultural y social, y cómo esa interrelación se ha reflejado especialmente a partir de la segunda mitad del siglo $X X$, con la toma de conciencia de género y sujeto histórico por los seres humanos, en los cambios sociales que afectan a esa dualidad de la familia como objeto y sujeto racional y emocional.

Precisamente, esos cambios experimentados por la evolución de los estudios de género han dado lugar a políticas de cambio social, en las que tienen un papel fundamental los Planes de Igualdad de Oportunidades, como demuestran en su artículo Juan José García Escribano, profesor de la Universidad de Murcia (España), e Inmaculada Concepción Sánchez Ruiz, también de la Universidad de
Murcia (España). A través del análisis del contenido de los Planes de Igualdad de distintos municipios de la Región de Murcia, ponen de relieve la incidencia que la legislación en igualdad de oportunidades tiene para alcanzar los objetivos de cambio social y cultural tan necesarios en la consecución de la igualdad real entre mujeres y hombres. Inciden en la necesidad de ampliar las medidas que recogen los Planes, con elementos complementarios imprescindibles para impulsar y garantizar políticas igualitarias verdaderamente eficaces y coherentes, capaces de generar cambios sociales que alcancen a las estructuras más profundas de la sociedad en lo que respecta a la igualdad de género, que repercute de manera decisiva en los cambios familiares.

Desde la perspectiva del papel de la acción social se estudia la crisis en la promoción de bienestar que ocasiona la COVID-19, como muestran los autores Jorge M. L. Ferreira y Maria João Pena, ambos profesores del Instituto Universitario de Lisboa (ISCTE-IUL) (Portugal), en el artículo "La familia: un recurso de intervención social en tiempos de incertidumbre". Reflexionan sobre el papel profesional del Trabajo Social en el ámbito de la familia, y las diversas problemáticas a las que ha de enfrentarse para promover y lograr una mayor inclusión social en la aplicación de los derechos humanos para un desarrollo social y humano más efectivo, que se ha visto subvertido por la pandemia. Por ello, subrayan la necesidad de repensar la protección social, especialmente en lo que ha afectado a la familia en algunos de sus entornos, como el de regulación del teletrabajo, la respuesta a la informalidad y la promoción de una mayor disposición de la sociedad a movilizar recursos financieros para la minimización de riesgos a través de la Seguridad Social, haciendo necesario el diseño de políticas más equitativas y sostenibles, capaces de afrontar situaciones de incertidumbre sobrevenidas como la pandemia.

El artículo de Enrique Pastor Seller, Catedrático de Trabajo Social de la Universidad de Murcia (España), ahonda en los problemas que plantea la pandemia en las familias vulnerables. En su artículo "Políticas sociales de protección a las familias en dificultad en tiempos de pandemia", señala que la pandemia ha alterado extraordinariamente las realidades familiares y las estrategias de cuidado, poniendo en evidencia las debilidades de las políticas de protección social en general, y familiares en particular. Analizando los cambios en la estructura y comportamientos familiares, la exclusión social de los hogares, así como las políticas y programas de protección que desarrollan las administraciones públicas españolas destinadas a familias con mayores dificultades sociales, constata, en sus resultados, la escasez, la insuficiencia en cobertura y cuantía, o la fragmentación y desigualdad en los territorios españoles, haciendo necesario el incremento de las coberturas, de la calidad de los servicios y de las prestaciones sociales para mejorar la vida familiar, especialmente en situaciones que sobrepasan los límites de la normalidad, como la ocasionada por la pandemia.

Imprescindible para abordar la interrelación entre la familia y el cambio social es su estudio desde la educación y la infancia, en la que inciden necesariamente las transformaciones experimentadas por la familia a lo largo de la Historia. Carmen M. Cerdá Mondéjar, profesora de la Universidad de Murcia (España), analiza esta cuestión en su 
artículo "Infancia, familia y educación: análisis histórico y cambio social". En él muestra la centralidad que adquiere la infancia tanto en el espacio privado como en el público, considerando las repercusiones que los cambios políticos, sociales, económicos, demográficos y culturales ejercen sobre la institución familiar. Para ello, la autora presenta las dificultades inherentes al estudio historiográfico de la infancia, subrayando los numerosos fenómenos, aspectos y problemáticas que se han derivado de ello, desde la medicina hasta el trabajo infantil, por ejemplo. Igualmente, se analiza la trayectoria histórica de la educación, desde el pensamiento filosófico de la Antigüedad Clásica hasta el tiempo presente, a través del que se ha ido consolidando la educación en la infancia como la vía imprescindible para mejorar la Humanidad, demostrando, sin embargo, que, pese a la conciencia de la vulnerabilidad de la infancia y la relevancia de la educación, siguen existiendo las lacras de pobreza, marginación y explotación en la infancia, y consecuentemente en su relación familiar, que sostienen las desigualdades humanas en el mundo.

Este monográfico sobre Familia y Cambio Socialmuestra una amplia y profunda panorámica científica y social sobre los más diversos problemas que afectan a la dualidad que caracteriza el estudio de la familia, como objeto y sujeto de los cambios y transformaciones que viene experimentando la Humanidad a lo largo de la historia. Se pone de relevancia la necesidad de conocer, explicar e interpretar los conocimientos y las acciones humanas desde el pasado, para entender el presente y seguir proyectando el futuro igualitario esperado por el sueño de la equidad entre la razón y la emoción.
Bibliografía

HERNÁNDEZ FRANCO, J. e IRIGOYEN LÓPEZ, A. (eds.): El giro de la familia: Homenaje historiográfico a Francisco Chacón Jiménez, Murcia, Universidad de Murcia.

LINTON, R. (1977): "Introducción. La historia natural de la familia”, en E. Fromm; M. Horkheimer y T. Parsons (eds.), La Familia. Barcelona, Ediciones Península, pp. 5-29.

PICÓ, J. y SANCHIS, E. (2003): Sociología y Sociedad. Madrid, Editorial Tecnos.

REHER, D. S. (1996): La familia en España, pasado y presente. Madrid, Alianza Editorial.

VALERO, A. (1995): "El sistema familiar español. Recorrido a través del último cuarto de siglo", Revista Española de Investigaciones Sociológicas, 70, pp. 91-105. 